\title{
CRIAÇÃO DO PROTÓTIPO DE UM DISPOSITIVO POKA YOKE PARA UMA EMPRESA DO RAMO ALIMENTÍCIO
}

\author{
André Vítor da Silva Rodrigues (UFCG) rodrigues.and3@gmail.com \\ Bárbara Valéria Pereira Lins (UFCG) barbaravplins@gmail.com \\ Bruno Victor Delmondes de Moura (UFCG) brunodemoura_@hotmail.com \\ Lais de Sousa Barroso (UFCG) laissousa9875@gmail.com \\ Priscilla Kelly Santos de Oliveira (UFCG) priscilla.santos14@hotmail.com
}

\begin{abstract}
Resumo
O presente artigo tem por objetivo a criação de um protótipo de dispositivo Poka Yoke para uma empresa do ramo alimentício a fim de sanar erros e falhas decorrentes do processo de embalagem de pipocas e salgadinhos e minimizar as perdas geradas a partir disso. O protótipo foi elaborado com o hardware livre Arduino, que irá detectar uma marca preta com posicionamento exato na linha de corte da embalagem e se não a detectar, parará a máquina, evitando prejuízos com matéria prima, produto final, tempo e custo de mão de obra.
\end{abstract}

Palavras-Chaves: Poka Yoke. Protótipo. Qualidade.

\section{Introdução}

A busca pela melhoria contínua realizada pelas empresas na atualidade visa garantir eficiência frente à concorrência. Para certificar a maximização da eficiência e eficácia na execução das ferramentas de melhoria, pode-se observar as seguintes questões: determinar as condições em que as ferramentas se tornam inconciliáveis, verificar as vantagens e desvantagens de cada ferramenta e delimitar as condições de aplicabilidade de cada ferramenta. (JUNIOR; COSTA; SOUSA; FILHO; FILHO, 2017)

A preocupação atual das organizações é a melhoria da qualidade referente ao seu desempenho. Há um conjunto de ferramentas aptas para auxiliar as empresas a atingirem esse objetivo, para prevenção e detecção de falhas, dentre elas, o presente projeto abordará o sistema à prova de erros Poka Yoke. O objetivo deste trabalho é a criação do dispositivo Poka Yoke, desenvolvido a partir de um hardware livre (o Arduino), para prevenir falhas no processo de embalagem de pipocas e salgadinhos e 
assim, maximizar os níveis de eficiência no processo produtivo e minimizar as perdas e custos desnecessários à organização.

\section{Referencial Teórico}

\subsection{Qualidade}

Qualidade é um conjunto de atributos presentes em produto ou serviço capaz de atender às necessidades do cliente, estando disponível em tempo, forma e lugar certos, por um preço competitivo (CAMPOS, 1992). Em uma análise recente, Maximiano (2010) afirma que estes conceitos continuam atuais, visto que a qualidade, no enfoque contemporâneo, deve ser definida a partir das necessidades e desejos dos consumidores.

Segundo Carvalho et al (2005), a qualidade passou por algumas eras e foi evoluindo até nossos dias, são elas: Inspeção; Controle estatístico do processo; Garantia da qualidade e Gestão total da qualidade. Com o tempo chegou-se à conclusão de que a inspeção era uma técnica cara e ineficaz, surgindo então o Controle estatístico do processo, onde o foco era controlar a qualidade através de métodos estatísticos, com ênfase no controle da variabilidade do processo.

Através de estudos foi enfatizada a necessidade de controlar toda cadeia de fabricação desde o projeto, caracterizando a garantia da qualidade, assim todos os departamentos focaram no planejamento, medição da qualidade e desenvolvimento de programas com o intuito de garantir a qualidade. A última era persiste até os dias atuais, sendo chamada de gestão da qualidade. Esta era "consiste no conjunto de atividades coordenadas para dirigir e controlar uma organização com relação à qualidade, englobando o planejamento, o controle, a garantia e a melhoria da qualidade”. (Carvalho et al, 2005).

Desta forma que o termo qualidade tem sido utilizado em diversas situações, nem sempre tendo uma definição clara e objetiva. Ou seja, a qualidade não é simples de ser definida, é aparentemente intuitiva. Sua interpretação depende do ponto de vista de

quem a analisa. É comum um produto/serviço de qualidade para uma pessoa e não ter para outra (CARVALHO, 2007).

\subsection{Dispositivo Poka Yoke}

Os mecanismos ou dispositivos Poka Yoke são também denominados de mecanismos de prevenção de erro ou a prova de falha; têm sua origem na língua japonesa das 
palavras yokeru (evitar) e poka (erro inadvertido) e são utilizados há muito tempo pela indústria manufatureira japonesa (CARLAGE e DAVANSO, 2001).

O conceito do poka yoke foi concebido inicialmente por Shingo (1996), verificando que as características de controle em um determinado produto eram conduzidas, fundamentalmente, por meio de três técnicas baseadas em inspeção: inspeção por julgamento, inspeção informativa e inspeção na fonte.

“Originalmente tratado como baka yokes (à prova de bobos) o sistema poka yoke tinha por objetivo prevenir o erro humano no trabalho, visto como a principal causa dos defeitos" (SHIMBUN, 1988). "Com a evolução dos conceitos acerca dos sistemas poka yokes divergências com relação ao conceito são verificadas. Há autores que entendem que os poka yokes são limitados a dispositivos físicos que controlam defeitos" (BENDELL et al., 1995), outros tem uma visão abrangente e entendem os mesmos como sistemas de garantia de qualidade e redução de variabilidade (MCGEE, 2005).

Segundo Junior, Costa, Sousa, Moraes e Araújo (2017), Poka Yoke é constituindo um recurso que indica ao operador o modo adequado para realizar uma determinada operação, ou seja, um mecanismo de detecção de erros que bloqueia as principais interferências (normalmente decorrentes de erros humanos) na execução da operação. Estes dispositivos caracterizam-se por serem utilizados num regime de inspeção a $100 \%$; dispensarem a atenção permanente do operador relativamente ao produto que está a ser processado; reduzirem ou eliminarem defeitos através das ações corretivas imediatas e serem simples e de baixo investimento.

Dentro da manufatura tem como funções básicas a paralisação de um sistema produtivo (máquina, linha, equipamento etc.); o controle de características pré-estabelecidas do produto e/ou processo e a sinalização quando da detecção de anormalidades. Tais funções básicas são utilizadas para prevenir um defeito, impedindo a sua ocorrência ou detectando-o após o seu evento, podendo, assim, serem classificadas (MORAES, 1996) como Função Reguladora ou Mecanismos de Detecção. 
Figura 1 - Esquematização das funções dos dispositivos Poka Yoke

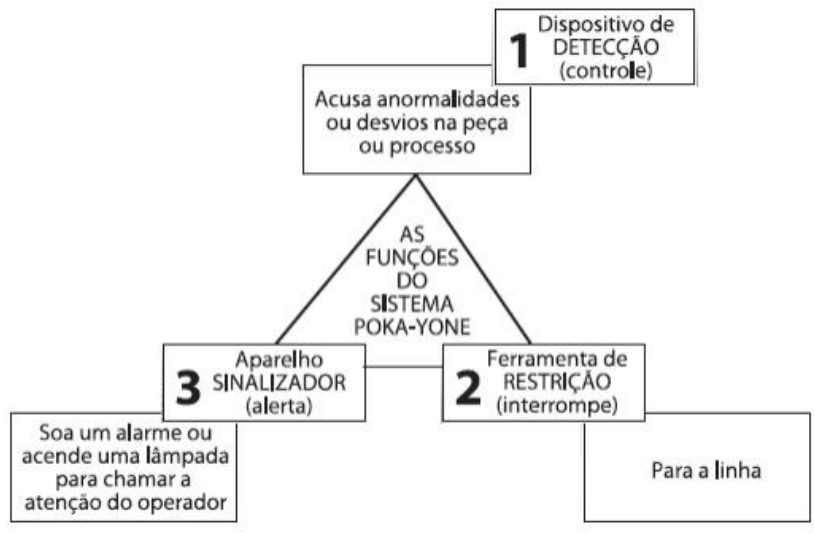

Fonte: (MORAES, 1996)

Na figura 2 que explica a aplicação do Poka Yoke em um processo de produção como sistema ante erro que controla o produto, onde existem peças mal soldadas (sem veio) e a instalação de um batente para detectar peças sem veio, que são segregadas do fluxo de produção. É um sistema ante erro que controla o produto.

Figura 2 - Exemplo de aplicação de Poka Yoke controlando o produto
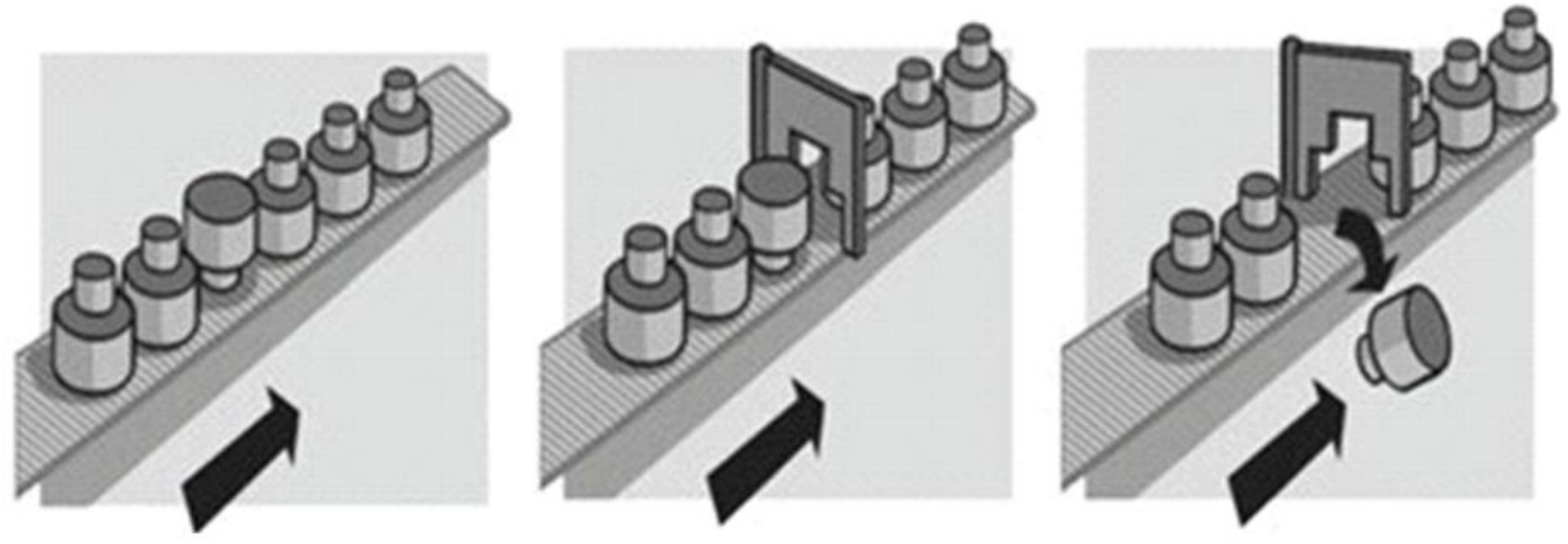

Fonte: <https://pjufmg.com.br/blog/poka-yoke-sua-empresa-a-prova-de-erros/>

\subsection{Formas de Defeitos e Inspeções}

Segundo Junior, Costa, Sousa, Filho e Filho (2017), os defeitos de qualidade impossibilitam a aceitação do cliente em relação ao produto final. No contexto de produção, os defeitos acontecem quando o produto não está nos parâmetros de qualidade estabelecidos, por exemplo, um dispositivo eletrônico que não ligará por causa de um curto na placa de circuito. Alguns dos defeitos que se pode citar são:

- Defeitos Isolados: acontece uma única vez; 
- Defeito Serial: ocorre repetidamente, quando uma peça mal posicionada ocasiona uma série de produtos defeituosos. As inspeções quantitativas e qualitativas frequentes nas máquinas por si só não são suficientes para minimizar os defeitos. Isso ocorre porque as falhas são produzidas durante o processo e não há modo de haver redução sem o uso de métodos que impossibilite a geração de erros;

\subsection{Arduino}

O Arduino foi criado em 2005 pelo italiano, Massimo Banzi, e outros colaboradores. De acordo com SOUZA (2013), o Arduino é composto por hardware e software, sendo o primeiro a placa sobre a qual são montados os projetos (prototipagem) e o último o programa no qual será feita a programação (sketch) que nada mais é que a sequência de comandos para coordenar as funções que o Arduino vai executar depois, a programação feita pelo projetista é enviada posteriormente à placa (upload).

Com o objetivo de criar um dispositivo para controlar projetos e protótipos construídos de uma forma mais acessível do que outros sistemas disponíveis no mercado. A plataforma Arduino consiste em uma plataforma Open-source baseada em hardware e software para as áreas de automação e robótica (SILVA, 2014).

Figura 3 - Placa Arduino UNO R3 (utilizada no projeto)

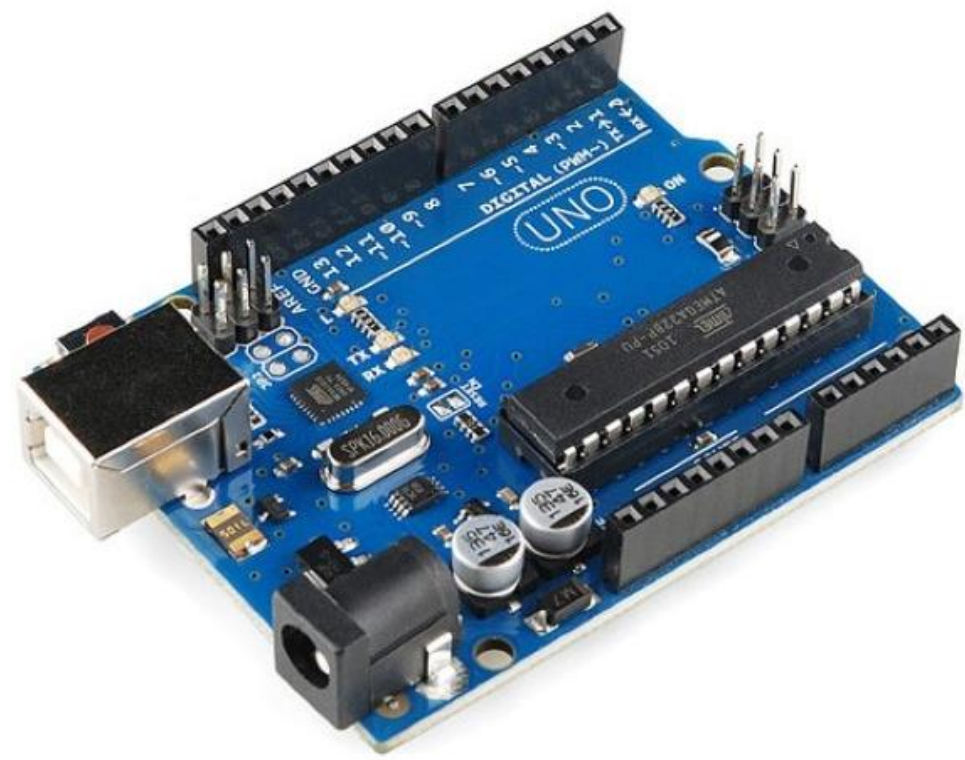

Fonte: < https://www.filipeflop.com/produto/placa-uno-r3-cabo-usb-para-arduino/> 
Conforme especifica SOUZA (2013), a placa apresenta 14 pinos de entrada e saída (digitais), que segundo o autor serão usados de acordo com o projeto a ser executado e com sua respectiva programação; há também 6 pinos de entrada analógica, que receberão ‘valores analógicos', e 6 pinos de saídas analógicas, embora os pinos digitais, por modulação PWM, também podem ser usados como saídas analógicas.

\section{Metodologia}

O estudo foi realizado em uma empresa do ramo alimentício na região do Pajeú, mais precisamente na cidade de Serra Talhada, Pernambuco. Foram realizadas visitas técnicas e observações diretas a fim de identificar possíveis erros ou falhas no processo produtivo almejando a criação de um Poka Yoke, dispositivo de controle e prevenção de erros ou falhas.

Após a identificação de uma falha no processo de embalagem de pipocas e salgadinhos que acarretava perdas e custos desnecessários a organização, realizou-se pesquisas bibliográficas com o intuito de constatar o tipo de falha e, posteriormente, desenvolveuse o dispositivo Poka Yoke usando Arduino, onde foi elaborado um protótipo simulando como o dispositivo atuaria no maquinário.

Foi criado um sistema, que conectado ao maquinário de embalagem, deverá desligá-lo a mínima percepção de erro, nesse caso, ausência de reconhecimento. Em seu estágio de prototipagem, o sistema em análise tem a sua estrutura composta por fios, LED (diodo emissor de luz), um buzzer (componente eletrônico que emite sinais sonoros), módulo de relé (componente responsável por ligar ou desligar a máquina), resistor de $10 \mathrm{~K}$ ohms, módulo do sensor LDR (setor fotovoltaico) e o micro controlador Arduino que irá interligar todos os componentes e comandar toda a parte lógica do sistema por meio da linha de programação que pode ser armazenada a ele.

\section{Resultados}

O dispositivo foi idealizado mediante a observação do processo produtivo, onde identificou-se uma falha recorrente no processo de embalagem das pipocas e salgadinhos. Esse dispositivo vai realizar a identificação de uma marca preta que deverá estar localizada exatamente na linha de corte das embalagens, então terá que disparar (desligar) a máquina e emitir sinais sonoros quando não reconhecer essa marca, tendo em vista que, se a embalagem for cortada em outro local, o produto que está dentro da 
mesma cairá sobre a esteira, gerando perdas de matéria-prima e produto final, já que esse processo acontece de forma rápida e o tempo de resposta do funcionário é lento, desde a percepção da falha até o desligamento do maquinário, além de gerar custos adicionais excessivos, principalmente com mão-de-obra.

O protótipo criado foi testado individualmente no laboratório de automação e obteve bom funcionamento em seus testes, o aparelho disparou todas as vezes quando não identificou a faixa preta mencionada anteriormente, esta que é a marca para o corte da embalagem. Então, para a criação e implementação do dispositivo na máquina de embalagens, faz-se necessário que o desenvolvam usando o protótipo como modelo e assim, realizar os testes de qualidade diretamente na máquina para verificar a redução dos erros.

Figura 4 - Protótipo

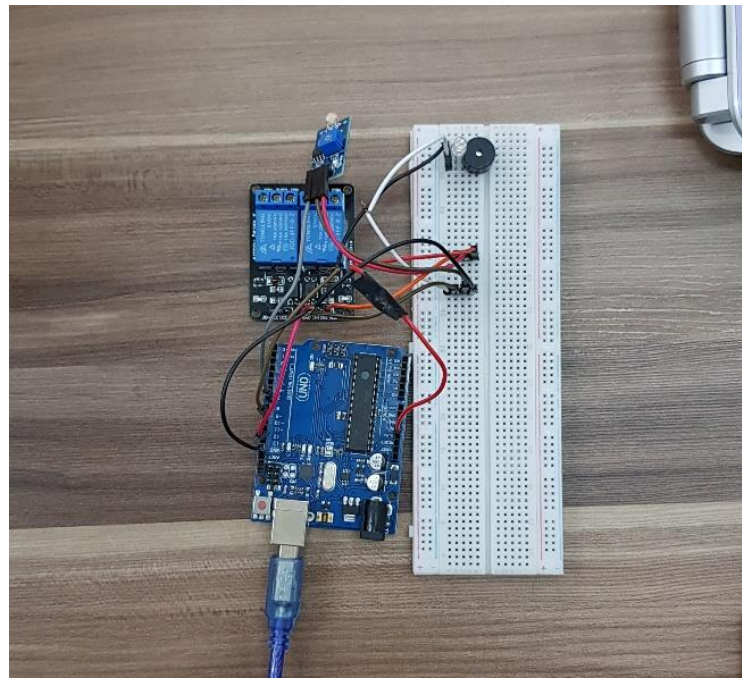

Fonte: autoria própria

\section{Considerações Finais}

Com a criação do protótipo Poka Yoke para introdução no processo de embalagem de uma empresa do ramo alimentício, foi possível identificar a relevância em acoplar um mecanismo a prova de falhas e erros em uma máquina de grande importância para a organização, visto que a mesma apresenta falha que causa custos com perda de produto final, embalagem, tempo e mão de obra, e tem como principal objetivo, que o dispositivo que será criado a partir do protótipo tenha fácil aplicabilidade e tenda a chegar a uma meta de defeitos ou perda mínima. 
A metodologia da aplicação do Poka-Yoke contribui para melhorar a qualidade do produto fornecido, reduzindo os riscos totais do processo visando à busca por práticas de melhoria contínua nas organizações atuais.

\section{REFERÊNCIAS}

BHAMU, Jaiprakash. SANGWAN, Kuildip Singh. Manufatura enxuta: revisão de literatura e questões de pesquisa. International Journal of Operations \& Production Management, 34:7, p. 876-940, 2014.

BENDELL, T., PENSON, R., CARR, S. The quality gurus - their approaches described and considered. Managing Service Quality, v.5, n.6, p.44-48, 1995.

CAMPOS, Vicente Falconi. TQC: Controle da Qualidade Total: no estilo japonês. Belo Horizonte, Fundação Cristiano Ottoni, 1992, p. 20-145.

CARlage, F. A; DAVAnSo, J. C. A Utilização de Dispositivos à Prova de Erros: Poka-Yoke Empregado na Melhoria de Desempenho de Processos de Manufatura.Conferência Brasileira de Engenharia de Manutenção, 2001.

CARVALHO, M. et al. Gestão da Qualidade - teoria e casos. Rio de Janeiro: Campus, 2005.

CARVALHO, M. Mapeando a ISO 9001 para o CMMI, Trabalho de Conclusão de Curso, Faculdade Lourenço Filho, Fortaleza, 2007.

MAXIMIANO, Antônio César Amaru. Teoria Geral da Administração: da revolução urbana à revolução digital. $6^{a}$ ed. São Paulo: Atlas, 2010, p. 1-86.

MIYAKE, Dario Ikuo. Melhorando o processo: Seis Sigma e Sistema de Produção Lean. In ROTONDARO et al. Seis Sigma - Estratégia Gerencial para melhoria de processos, produtos e serviços. São Paulo: Editora Atlas, 2002.

MORAES, B. A glossary of terms encountered in quality and customer service. International Journal of Health Quality Assurance, v.9, n.5, p.24-36, 1996.

MCGEE, D. Lean and Six Sigma: A Holistic Approach to Process Improvement. In.: ASQAMERICAN SOCIETY FOR QUALITY CONGRESS, PROCEEDINGS... Denver, USA. Disponível em: <https://pjufmg.com.br/blog/poka-yoke-sua-empresa-a-prova-de-erros/> Acesso em: 30 de nov. de 2019.

SHIMBUN, N.K. Poka-yoke: Improving Product Quality by Preventing Defects. Portland, MA: Productivity Press, 1988. Título Original: Pokayoke dai zukan. 
SHINGO, Shigeo. Zero Quality Control: Source Inspection and the Poka-Yoke System. Cambridge, Massachusetts, Productivity Press, 1996. Disponível em: <https://www.filipeflop.com/produto/placa-unor3-cabo-usb-para-arduino/> Acesso em: 03 de dez. de 2019.

SILVA, J. L. S.; Melo, M. C.; Camilo, R. S.; Galindo, A. L; e Viana, E. C. 2014. Plataforma Arduino integrado ao PLX-DAQ: Análise e aprimoramento de sensores com ênfase no LM35. XIV Escola Regional de Computação Bahia, Alagoas e Sergipe (ERBASE). Feira de Santana, BA. 2014.

SOUZA, Fábio. Arduino - Primeiros Passos, 2013. Disponível em: <https://www.embarcados.com.br/arduino/> Acesso em: 03 de dez. de 2019. 